\title{
Antagonistic Activity of Fungal Endophytes Isolated from Garcinia atroviridis against Colletotrichum gloeosporioides
}

\author{
Nur Afeeqah Binti Mohamed Zanudin ${ }^{1,2}$, Nor'Aishah Hasan ${ }^{2 *}$, Patahayah Binti Mansor ${ }^{3}$ \\ ${ }^{1}$ Faculty of Applied Sciences, Universiti Teknologi MARA, Shah Alam, Selangor, Malaysia \\ ${ }^{2}$ Faculty of Applied Sciences, Universiti Teknologi MARA, Cawangan Negeri Sembilan, Kampus Kuala Pilah, Negeri Sembilan, \\ Malaysia \\ ${ }^{3}$ Laboratory of Mycology and Pathology, Forest Biodiversity Division, Forest Research Institute Malaysia, Kuala Lumpur, Malaysia
}

ARTICLE INFO

Article history:

Received October 30, 2019

Received in revised form June 1, 2020

Accepted June 15, 2020

\section{KEYWORDS:}

Biocontrol agent,

Colletotrichum gloeosporioides,

endophytic fungi,

Garcinia atroviridis

\begin{abstract}
The extensive use of synthetic fungicides in controlling plant disease generates detrimental impacts on the environment and human health. In response to this problem, an alternative method was developed, known as biological control using antagonistic microorganisms. Since investigation on fungal endophytes of Garcinia atroviridis is still unclear, it was chosen for the study. The aim of the present work was to evaluate biocontrol potential of endophytic fungi against Colletotrichum gloeosporiodes, a phytopathogen that caused anthracnose disease. A total of 92 endophytic fungi were isolated from different tissue parts of Garcinia atroviridis including leaves, petioles, branches, and fruits. Results demonstrated that, most of endophytic fungal isolates showed some inhibitory action over the growth of $C$. gloeosporiodes during dual culture growth. Endophyte isolate F14 showed the highest antagonistic activity against Colletotrichum gloeosporiodes with $\mathbf{6 7 . 3 8 \%}$ percentage inhibition radial growth (PIRG). However, 7 out of 92 isolates showed no inhibitory effect against Colletotrichum gloeosporiodes. In conclusion, endophytic fungi isolated from $G$. atroviridis indicate the potential as biocontrol agents. It is hoped that the finding of isolated endophytic fungi in this study with antagonistic activity against anthracnose pathogen may be used in biocontrol programmes of plant disease in the region.
\end{abstract}

\section{Introduction}

Garcinia atroviridis is locally called as Asam gelugur. Belongs to the family of Clusiaceae, it can be found in Malaysia, Myanmar, India and is widely cultivated in Sumatera Island as one of export commodity purposes (MyBIS, n.d; Bayu et al. 2018). Other than being used in cooking as flavouring agent to replace tamarind, G. atroviridis is also being used traditionally in many ways to promote human health (Sultana et al. 2014). The plant parts has been used by the old folks as an abdominal reliever during pregnancy, cough and throat irritation remedy, to combat dandruff problem and can enhance better blood circulation in body (Taher et al. 2017). Based on Sultana et al. (2014); Taher et al. (2017); Bayu et al. (2018), the fruit of this plant contains many organic compounds but the most interesting is the

* Corresponding Author

E-mail Address: aishahnh@uitm.edu.my hydroxycitric acid. This acid has been commercialized under weight management product. Besides that, the extracts from different plant parts have antibacterial, antifungal, antioxidants, and antitumor potential. However, investigations based on endophytic microorganism associated with G. atroviridis is still limited and needs to be explored (Sim et al. 2010).

Anthracnose is one of the most problematic and economically harmful plant diseases occur on a variety of crops. This disease infected most of the plant parts such as fruits, leaves, stems, and flowers (Kimaru et al. 2018). Anthracnose is favoured by humid, wet, warm condition and transmitted by rain splash, moist wind and infected seeds (Sharma and Kulshrestha 2015). There are several causal agents of this disease that have been documented, but the most commonly known is species of the genus Colletotrichum including $C$. gloeosporioides, $C$. acutatum, C. capsici, and G. musae (Than et al. 2008; Abd-Elsalam et al. 2010; Sarkar 2016; Waghunde et 
al. 2017). These species causes considerably damage to large number of crops and tropical fruits such as coffee, chilli, strawberry, mango, banana, and avocado (Freitas et al. 2013; Oo and Oh 2016; Uddin et al. 2018). It is characterised by the development of dark sunken necrotic lesions on affected plant part (Crump 2009). The critical phases for disease control are during flowering and fruit set, and after harvest which requires both pre and post treatments.

Commercial synthetic fungicides such as propineb, difenoconazole, chlorothalonil, propiconazole, and mancozeb are used to overcome anthracnose caused by Colletotrichum sp. on various fruits and vegetables (Crump 2009). These chemicals are undoubtedly effective in controlling the disease, however, many of them have been banned in some countries due to their debits such as causing acute poisoning, birth defects, and endocrine distruption (PAN 2017). Hence, interest has been developed to create an alternative way that is safe and effective to be used in plant disease management. Replacing fungicides with biological control agents (BCAs) has been acknowledge for years as it could offer better results and cause no effect towards environment (Talapatra et al. 2017). It is primarily relies on the use of antagonistic organism that universally or specifically target the pathogen.

Endophytes are microorganisms that colonize within the plant cells without causing any harm and eventually establish mutualistic relationship with its plant host (Padhi et al. 2013). The host supplying nutrients and protection to endophytes while in return, endophytes producing novel bioactive metabolites which help in improving the host's ability to tolerate with biotic and abiotic stresses, promoting the plant growth and enhancing the resistance of its host to various types of pathogens (Tan and Zou 2001; Patra et al. 2016). Studies done by the researches demonstrated that endophytic microorganisms could be recognized successful biopesticides in controlling plant damage caused by the phytopathogens (Phongpaichit et al. 2006; Bivi et al. 2010; Landum et al. 2016; Marcellano et al. 2017). To date, all plants that have been studied from various habitats, harbour one or more endophytic microorganisms (Jia et al. 2016). Therefore, the focus of this study was to test antagonistic activity of endophytic fungi isolated from Garcinia atroviridis against Colletotrichum gloeosporioides ( $C$. gloeosporioides).

\section{Materials and Methods}

\subsection{Samples Collection}

Sampling activity was carried out by following method by (Martin and Dombrowski 2015). Different parts (leaf, petiole, branch, fruit) of healthy host plants, Garcinia atroviridis were collected from Nasuha Herbal Farm, Muar, Johor, Malaysia. Samples were stored in an aseptic zipper bags separately during collection.

\subsection{Isolation of Fungal Endophyte}

All the plant tissues were thoroughly washed with running water and cut into $0.5 \mathrm{~cm}$ pieces. The method described by Zheng et al.(2017) were slightly modified and used for surface sterilization. The samples were surface sterilized by following series of immersion sequential steps: $70 \%$ Ethanol for 2 minutes, 2\% Sodium Hypochlorite for 3 minutes, sterile distilled water for three times and allowed to dry on sterilized filter paper. After drying, the small pieces (3-5) of each plant parts were placed on Potato Dextrose Agar (PDA) supplemented by chloramphenicol. The plates were invertedly incubated for 2 weeks at $28^{\circ} \mathrm{C}$ for fungal development. Each colony that appeared from the edge of tissues was continuously subcultured in order to obtain pure culture. Colonization rate was calculated by dividing the total number of plant segments infected by fungal endophyte over total number of segments incubated. Isolation rate was determined as the number isolates obtained from plant segments divided by the total number of segments incubated (Sun et al. 2008; Pal et al. 2012; Wu et al. 2019).

\subsection{Preparation of Pathogenic Fungus}

Antagonistic activity of all endophytic fungi was evaluated against Colletotrichum gloeosporioides (FRIM 1319), which was obtained from Laboratory of Mycology and Pathology, Forest Research Institute Malaysia, Kepong. The fungal pathogen was sub-cultured on PDA plate and incubated at $28^{\circ} \mathrm{C}$. The mycelial plugs of fungal pathogen were stored in $30 \%$ glycerol at $-80^{\circ} \mathrm{C}$ for long term preservation. 


\subsection{In vitro Evaluation of Endophyte Fungi against Colletotrichum gloeosporioides}

The antagonistic potential of endophytic fungal isolates was assessed through direct confrontation method in accordance to Katoch and Pull (2017). The experiment was performed in triplicate and the mean values were recorded. A $5 \mathrm{~mm}$ agar plug of 7 day old endophyte fungus and pathogen were co-cultured at opposite site in PDA plate. The pathogen alone (without endophyte) was served as control. All the plates were invertedly incubated at $28^{\circ} \mathrm{C}$ for two weeks. The radial growth of pathogen cultured with/without endophyte fungal was measured daily. Then, the data was transformed into percentage inhibition of radial growth (PIRG) using the formula:

$$
\operatorname{PIRG}(\%)=\frac{\mathrm{CDC}-\mathrm{CDT}}{\mathrm{CDC}} \times 100
$$

Where,

CDC :radial growth of pathogen colony in the absence of endophyte (measured in $\mathrm{cm}$ ) CDT :radial growth of pathogen colony in the presence of endophyte (measured in $\mathrm{cm}$ )

The data obtained from the observation on the fungal colony radial was subjected to analysis of variance (2-way ANOVA). The means were separated by Tukey's test at $\mathrm{p}<0.05$ with SPSS statistical software.

\section{Results}

\subsection{Isolation of Fungal Endophytes}

A total of ninety two endophytic fungi were successfully isolated from different plant parts (branches, fruits, leaves, and petioles) of Garcinia atroviridis. Figure 1 shows the colonization frequency of endophytic fungi in branch (96.3\%) was higher

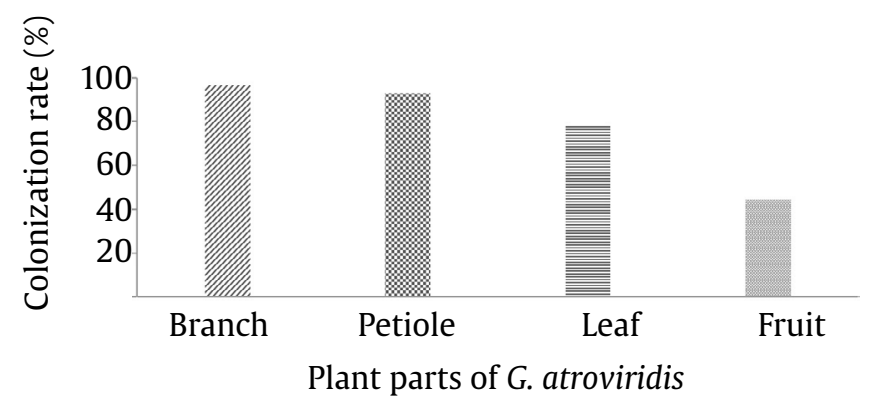

Figure 1. Colonization rate (\%) of endophytic fungi isolated from G.atroviridis as compared to petiole (92.6\%), leaf (77.85\%), and fruit (44.4\%). Similarly, endophytic fungi in branch recorded highest isolation rate (1.14), followed by petiole (1.11), leaf (0.67), and fruit (0.48) (Figure 2).

\subsection{Screening of Endophytic Fungi against Colletotrichum gloeosporioides in Dual Culture Assay}

The potential antagonistic activities of all endophytic fungi against $C$. gloeosporioides pathogen were investigated in dual culture assay. In dual culture plate, the percentage of inhibition radial growth (PIRG) of endophytes towards C. gloeosporiodes was observed on $7^{\text {th }}$ days and $14^{\text {th }}$ day of incubation. All the endophyte isolates showed different degrees of inhibition toward the mycelial growth of pathogen, ranging from $0.00 \%$ and $67.38 \%$ (Figure 3 ). Generally, all endophyte isolates showed inhibitory activity on the pathogen except for the seven isolates which were F7, F50, F61, F68, F76, F78, and F85. From all the tested endophyte isolates, only 14 endophytic fungi showed $>50 \%$ of PIRG and the others were categorised $<50 \%$ of PIRG (Table 1). The highest PIRG value was observed in F14 (67.38\%) and F65 isolates was recorded as the lowest PIRG value (5.08\%).

\section{Discussion}

Medicinal plants have been targeted for their endophyte microorganisms as the endophytes have capability of producing similar secondary metabolites as their plant host (Zhao et al. 2010; Nazir and Rahman 2018). These fungal endophytes are now great used by pratitioners in biological control practices against plant pathogens and pests. They have been investigated as potential biocontrol agents and proved to be successful antagonists towards

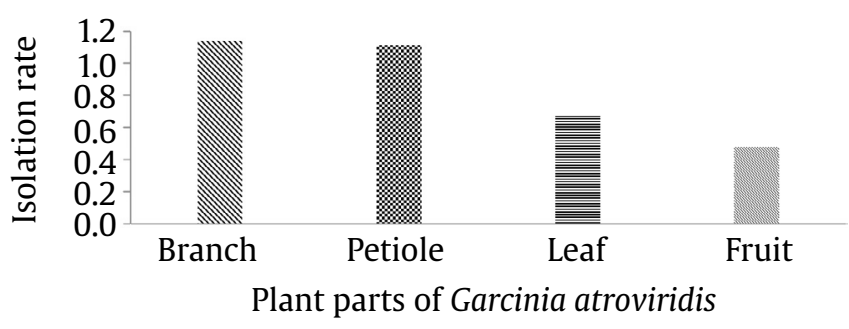

Figure 2. Isolation rate of endophytic fungi isolated from G. atroviridis 

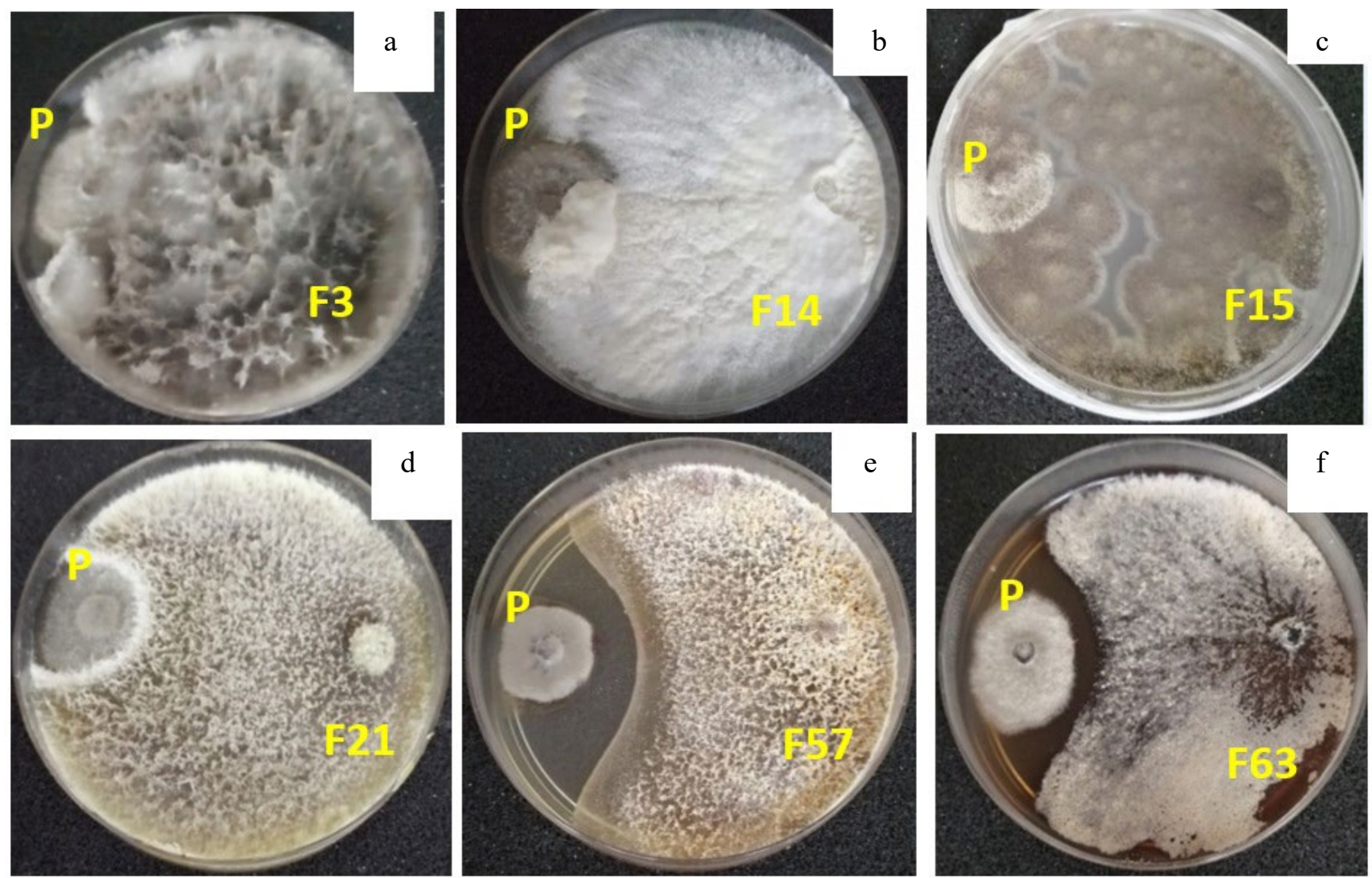

Figure 3. Antagonistic effect of endophytic fungi on C. gloeosporioides (P) after 14 days incubation in dual culture plate. (a) F3, (b) F14, (c) F15, (d) F21, (e) F57, and (f) F63

Table 1. Mean PIRG (\%) of antagonistic potential of endophytic fungi against $C$. gloeosporioides on dual culture test

\begin{tabular}{lll}
\hline $\begin{array}{l}\text { Endophytic } \\
\text { fungi }\end{array}$ & Day 7 (\%) & Day 14 (\%) \\
\hline F3 & $30.95^{\mathrm{a}} \pm 3.37$ & $58.36^{\mathrm{b}} \pm 0.66$ \\
F4 & $30.95^{\mathrm{a}} \pm 3.37$ & $53.95^{\mathrm{b}} \pm 5.58$ \\
F13 & $38.69^{\mathrm{a}} \pm 4.21$ & $51.32^{\mathrm{b}} \pm 1.86$ \\
F14 & $47.62^{\mathrm{a}} \pm 4.12$ & $67.39^{\mathrm{b}} \pm 4.22$ \\
F15 & $52.78^{\mathrm{a}} \pm 3.37$ & $64.39 \mathrm{~b} \pm 1.67$ \\
F19 & $38.10^{\mathrm{a}} \pm 6.73$ & $56.47^{\mathrm{b}} \pm 4.99$ \\
F20 & $36.91^{\mathrm{a}} \pm 4.30$ & $53.95^{\mathrm{b}} \pm 5.58$ \\
F21 & $44.44^{\mathrm{a}} \pm 4.81$ & $62.33^{\mathrm{b}} \pm 3.17$ \\
F47 & $20.63^{\mathrm{a}} \pm 5.62$ & $51.86^{\mathrm{b}} \pm 1.62$ \\
F53 & $28.57^{\mathrm{a}} \pm 6.19$ & $51.56^{\mathrm{b}} \pm 4.08$ \\
F57 & $42.26^{\mathrm{a}} \pm 0.84$ & $59.41^{\mathrm{b}} \pm 0.83$ \\
F63 & $21.03^{\mathrm{a}} \pm 4.18$ & $51.25^{\mathrm{b}} \pm 9.48$ \\
F70 & $41.67^{\mathrm{a}} \pm 6.87$ & $61.45^{\mathrm{b}} \pm 5.03$ \\
F95 & $50.00^{\mathrm{a}} \pm 0.84$ & $64.71^{\mathrm{b}} \pm 2.41$ \\
\hline Va
\end{tabular}

Values of PIRG (\%) are means from 3 replications. Means followed by the same letter in each row are not significantly different at $\mathrm{p}<0.05$ according to Tukey's test pathogens and phytophagous insects through many studies.

In this study, about 92 endophytic fungi were cultivated from $G$. atroviridis. The colonization rate was calculated on the purpose of comparing the degrees of infected by fungal endophytes between different plant parts while the isolation rate could demonstrated the fungal richness in a given sample of plant parts (Sun et al. 2008). Based on the results, branches demonstrated the highest isolation and colonization of endophyte isolates followed by petioles, leaves and fruits. The result was align with the study made by Sun et al. (2008) which reported that the colonization of endophytic fungi in branches is higher than the leaves. The same results were pointed out by Phongpaichit et al. (2006). In contrast to these studies, Yu et al. (2018) reported that endophytic fungi isolated from Camellia oleifera was highest in leaves compared to other parts of 
the plant. It can be said that the potential of fungal endophytes to colonize inter- or intracellular of plant is depends on their capability to utilize different substrates synthesize in different parts of the plant host (Sun et al. 2008; Pandey et al. 2014). This specific distribution has been looked as a strategy in order to reduce intense rivalry between the endosymbionts and preventing the plant host from an excessive population of endophytic microorganisms (Gimenez et al. 2007).

Dual culture assay is the basic method in order to assess antagonistic the pathogen tested (Rahman et al. 2010). This technique has been used in the studies done by (Devi and Singh 2015; Naidu et al. 2016; Yasmin et al. 2017). Results of direct inhibition test showed that 85 out of 92 endophytic fungi isolated from Garcinia atroviridis have the ability to inhibit the growth of $C$. gloeosporioides. In this study, fourteen endophytic fungi (Figure 1) were classified as strong antagonist that might have potential to be used in biocontrol management plan to combat anthracnose disease caused by the pathogen. Similarly, Ting et al. (2009) and Naidu et al. (2016) reported in their studies that endophyte isolates with percent of inhibition radial growth (PIRG) above 50\% against the pathogens were grouped as great antagonist. Although at first both endophytes and the pathogen were co-cultured in opposite direction, most of the endophyte mycelium grows towards the pathogen as the incubation period started and showed different patterns of interaction after two weeks as reported by Begum et al. (2008) and Naidu et al. (2016). Endophytic fungi have several mechanisms in order to reduce or suppress the growth of fungal pathogens such as competing nutrient or space, mycoparasitism and producing extracellular metabolites (Scott 2016; Hamzah et al. 2018). The hyperparasitism action of F14 isolate can be seen on the fifth day as its mycelium begun to in contact with the mycelial of the pathogen. The endophyte then started to overgrow the pathogen on day 8 and giving the highest PIRG (67.39\%) on day 10. The same mechanism reported by Lahlali and Hijri (2010) as the $R$. solani colony was entirely invaded by fungal endophyte of potato plant, T. atroviride. On the other hand, confrontational activity of Xylaria sp. and Phoma sp. on F. solani were demonstrated by secreting secondary metabolite into the agar which have adverse effect on the pathogen's growth (Hamzah et al. 2018).

\section{Conclusion}

Overall, there were ninety-two endophytic fungi were successfully isolated from the branches, petioles, leaves and fruits of Garcinia atroviridis. A total of 85 fungal endophytes demonstrated different degrees of antagonistic properties against anthracnose pathogen, Colletotrichum gloeosporoioides, where the F14 isolates could be the potential biocontrol agent for $C$. gloeosporioides as it has the highest PIRG (67.39\%). Finding in this study suggested the initial step in utilizing the isolates for inhibitory application in agriculture and forestry in the region.

\section{Acknowledgements}

The authors are highly grateful to Mycology and Pathology Labarotory of Forest Research Institute Malaysia (FRIM) for providing Colletotrichum gloeosporioides, Nasuha Herbal Farm, Muar, Johor, Malaysia for Garcinia atroviridis sample, and acknowledge Universiti Teknologi MARA (UiTM), Kampus Kuala Pilah for providing facilities throughout the research activity.

\section{References}

Abd-Elsalam KA et al. 2010. First morphogenetic identification of the fungal pathogen Colletotrichum musae (Phyllachoraceae) from imported bananas in Saudi Arabia. GMR 9:2335-2342.

Bayu ES et al. 2018. Flower morphology diversity of asam gelugur (Garcinia atroviridis griff, ex t. anders) accessions in several districts of North Sumatera, Indonesian. In: IOP Conference Series: Earth and Environmental Science, Vol 122. United Kingdom: IOP Publishing Ltd.

Begum MM. et al. 2008. Antagonistic potential of selected fungal and bacterial biocontrol agents against Colletotrichum truncatum of soybean seeds. Pertanika Journal of Tropical Agricultural Science 31:45-53.

Bivi MR et al. 2010. Control of Ganoderma boninense: a causal agent of basal stem rot disease in oil palm with endophyte bacteria In Vitro. International Journa of Agriculture and BIology 12:833-839.

Crump A. 2009. Pest Notes: Anthracnose. In : How to Manage Pests, Pests in Gardens and Landcapes. Available at: http://www.ipm.ucdavis.edu/PMG/PESTNOTES/ pn7420.html [Date assessed: 28 June 2019]

Devi NN, Singh MS. 2015. Endophytic fungi associated with traditional medicinal plants of Manipur. International Journal of Pharmaceutical Sciences Review and Research 33:127-132.

Freitas RL et al. 2013. Colletotrichum boninense causing anthracnose on coffee trees in Brazil. Plant Disease 97:1255-1258.

Gimenez C et al. 2007. Fungal endophytes and their role in plant protection. Current Organic Chemistry 11:707720. 
Hamzah TNT et al. 2018. Diversity and characterization of endophytic fungi isolated from the tropical mangrove species, Rhizophora mucronata, and identification of potential antagonists against the soil-borne fungus, Fusarium solani. Frontiers in Microbiology 9:91-17. DOI:10.3389/fmicb.2018.01707

Jia M et al. 2016. A friendly relationship between endophytic fungi and medicinal plants: a systematic review. Frontiers in Microbiology 7:1-14.

Katoch M, Pull S. 2017. Endophytic fungi associated with Monarda citriodora, an aromatic and medicinal plant and their biocontrol potential. Pharmaceutical Biology 55:1528-1535.

Kimaru SK et al. 2018. Morphological and molecular identification of the causal agent of Anthracnose disease of avocado in Kenya. International Journal of Microbiology 2018:1-10.

Lahlali R, Hijri M. 2010. Screening, identification and evaluation of potential biocontrol fungal endophytes against Rhizoctonia solani AG3 on potato plants. FEMS Microbiology Letters 311:152-159.

Landum MC et al. 2016. Antagonistic activity of fungi of Olea europaea L. against Colletotrichum acutatum. Microbiological Research 183:100-108.

Marcellano JP et al. 2017. Antibacterial activity of endophytic fungi isolated from the bark of Cinnamomum mercadoi. Pharmacognosy Journal 9:405-409.

Martin RC, Dombrowski JE. 2015. Isolation and identification of fungal endophytes from grasses along the Oregon Coast. American Journal of Plant Sciences 6:3216-3230.

Malaysia Biodiversity System (MyBIS) 2019. Available at https://www.mybis.gov/sp/8484. [Data assessed: 9 June 2019]

Naidu Y et al. 2016. In vitro antagonistic interactions between endophytic Basidiomycetes of oil palm (Elaeis guineensis) and Ganoderma boninense. Journal of Phytopathology 164:779-790.

Nazir A, Rahman HA. 2018. Secrets of plants: endophytes. International Journal of Plant Biology 9:43-46.

Oo MM, Oh SK. 2016. Chilli anthracnose (Colletotrichum spp.) disease and its management approach. Korean Journal of Agricultural Science 43:153-162.

[PAN] Pesticide Action Network 2017. Global Governance of Hazardous Pesticides to Protect Children:Beyond 2020. Available at http://www.indiaenvironmentportal.org. in/files/file/SAICM-PANAP-Children-and-Pesticides. pdf [Date assessed:10 June 2019]

Padhi L et al. 2013. Endophytic fungi with great promises: a review. Journal of Advanced Pharmacy Education and Research 3:152-170.

Pal A et al. 2012. Diversity and antimicrobial spectrum of endophytic bacteria isolated from Paederia foetida L. International Journal of Current Pharmaceutical Research 4:123-127.

Pandey PK et al. 2014. Fungal endophytes:promising tools for pharmaceutical science. International Journal of Pharmaceutical Sciences Review and Research 25:128138.

Patra JK et al. 2016. Endophytes: a treasure house of bioactive compounds of medicinal importance. Frontiers in Microbiology 7:1-8.

Phongpaichit S et al. 2006. Antimicrobial activity in cultures of endophytic fungi isolated from Garcinia species. FEMS Immunology and Medical Microbiology 48:367372

Rahman MA et al. 2010. Screening of Trichoderma isolates as a biological control agent against Ceratocystis paradoxa causing pineapple disease of sugarcane. Mycobiology 37:277-285.
Sarkar AK. 2016. Anthracnose diseases of some common medicinally important fruit plants. Journal of Medicinal Plants 4:233-236.

Scott M. 2016. Isolation and Characterization of Endophytic Microorganisms from Industrial Hemp Plant. [Dissertation]. Montreal, Canada: McGill University.

Sharma M, Kulshrestha S. 2015. Colletotrichum gloeosporioides: an anthracnose causing pathogen of fruits and vegetables. Biosciences Biotechnology Research Asia 12:1233-1246.

Sim JH et al. 2010. Molecular diversity of fungal endophytes isolated from Garcinia mangostana and Garcinia parvifolia. Journal of Microbiology and Biotechnology 20:651-658.

Sultana N et al. 2014. Review on some Malaysian traditional medicinal plants with therapeutic properties. Journal of Basic and Applied Sciences 10:149-159.

Sun JQ et al. 2008. Diversity and ecological distribution of endophytic fungi associated with medicinal plants. Science in China Series C: Life Sciences 51:751-759.

Taher $\mathrm{M}$ et al. 2017. Garcinia atroviridis - a review on phytochemicals and pharmacological properties properties. Marmara Pharmaceutical Journal 21:38-47.

Talapatra K et al. 2017. In vitro antagonistic activity of a root endophytic fungus towards plant pathogenic fungi. Journal of Applied Biology and Biotechnology 5:68-71.

Tan RX, Zou WX. 2001. Endophytes: rich source of functional metabolites. Natural Products Reports 18:448-459.

Than PP et al. 2008. Chilli anthracnose disease caused by Colletotrichum species. Journal of Zhejiang University SCIENCE B 9:764-778.

Ting ASY et al. 2009. Prevalence of endophytes antagonistic towards Fusarium oxysporum F. Sp. Cubense race 4 in various plants. American-Eurasian Journal of Sustainable Agriculture 3:399-406.

Uddin $\mathrm{N}$ et al. 2018. Management of anthracnose disease of mango caused by Colletotrichum gloeosporioides: a review. Acta Scientific Agriculture 2:169-175.

Waghunde RR et al. 2017. Endophyte mcrobes: a weapon for plant health management, In Panpatte DG et al. (Eds.) Microorganisms for Green Revolution. Singapore: Springer Nature Singapore Pte Ltd. pp. 303-325.

Wu $\mathrm{F}$ et al. 2019. Diversity estimation and antimicrobial activity of culturable endophytic fungi from Litsea cubeba (Lour.) Pers in China Forests 10:1-12.

Yasmin S et al. 2017. Biocontrol of bacterial leaf blight of rice and profiling of secondary metabolites produced by rhizospheric Pseudomonas aeruginosa BRp3. Frontiers in Microbiology 8:1895.

Yu J et al. 2018. Diversity and antifungal activity of endophytic fungi associated with Camellia oleifera. Mycobiology 46:85-91.

Zhao J et al. 2010. Endophytic fungi for producing bioactive compounds originally from their host plants. In $A$ Mendez-Villas (Eds.). Current Research, Technology and Education Topics in Applied Microbiology and Microbial Biotechnology. Spain: Formatex Research Center. pp. 567-576.

Zheng YK et al. 2017. Endophytic fungi harbored in Panax notoginseng: Diversity and potential as biological control agents against host plant pathogens of rootrot disease. Journal of Ginseng Research 41:353-360. 